\title{
Prevalence and associated factors of wasting among school children in Ethiopia: Multi-centered cross-sectional study
}

\author{
Wondwosen Molla $^{\mathrm{a}, *}$, Dirshaye Argaw ${ }^{\mathrm{b}}$, Robel Hussen Kabthymer ${ }^{\mathrm{b}}$, Aregahegn Wudneh ${ }^{\mathrm{a}}$ \\ ${ }^{a}$ Department of Midwifery, Dilla University, Dilla, Ethiopia \\ ${ }^{\mathrm{b}}$ School of Public Health, Dilla University, Dilla, Ethiopia
}

\section{A R T I C L E I N F O}

\section{Keywords:}

Wasting

Thinness

Nutrition

Malnutrition

Ethiopia

\begin{abstract}
A B S T R A C T
Background: Wasting is one of the two major anthropometric markers used to describe malnutrition, and it represents a low weight for height, which is commonly associated with disease, including food deprivation. Method: ology: School based cross-sectional study was conducted in Gedeo Zone, South Ethiopia. Multi-stage sampling technique was used to get a total of 500 children. Data was entered into Epidata version 3.1 and exported to Statistical Package for the Social Sciences (SPSS) version 23.0 for analyses. Wasting was assessed by measuring weight-for-height of equal to or less than minus two standard deviations (2 SD) below the mean of a reference WHO standard by using Anthro Plus 1.0.4 software program. Variables having p $<0.25$ at bivariate analysis were fitted to multivariable analysis. Multivariable logistic regression model was used at $95 \%$ confidence interval and with P-Value $<0.05$.

Result: The prevalence of wasting was found to be $18.2 \%$. Age AOR $=3.15,95 \% \mathrm{CI}(2.05,8.44))]$, sex [AOR $=$ $3.87,95 \% \mathrm{CI}(2.73,9.03)]$. Mothers' educational status [AOR 3.49 (95\%CI $(2.23,6.06))$ ] and having history of internal displacement $[\mathrm{AOR}=3.01$, $(95 \% \mathrm{CI}(2.17,5.31)]$ were significantly associated with wasting among school-age children.

Conclusions: About $18.2 \%$ of primary school children had wasted in this study. In this study, the age of children, maternal education, history of internal displacement, and sex of children were significantly associated with wasting. The interventions should be targeted with a special emphasis on the vulnerable groups of children (history of internal displacement). In addition, nutrition education must be considered.
\end{abstract}

\section{Background}

Child nutrition is as an indicator and a precondition for a country's investment in the future development of its social capital; as a result, guaranteeing optimal child growth and development is critical to a country's economic prosperity. ${ }^{1,2}$ Undernutrition is a leading cause of disease susceptibility, morbidity, and mortality in school-aged children, especially in resource-poor countries, where it accounts for half of all fatalities in this age group. ${ }^{3}$

Malnutrition is a condition that occurs when a person consumes a nutrient-poor or nutrient-rich diet. ${ }^{4}$ Wasting is also known as acute malnutrition, which is caused by fast weight loss and the inability to acquire weight.

Wasting, weight-for-height (WHZ) less than minus two standard deviations (2 SD) of WHO's child growth standards in children poses a serious threat to child survival and development, with the heightened risk of mortality. Reflects a nutritionally deficient state of recent onset related to sudden food deprivation or mal-absorption utilization of nutrients which results weight loss. ${ }^{5-7}$

Globally, nearly $6 \%$ of children had wasting ${ }^{8}$ and in 2018 , more than 49.5 million children under the age of five suffered from wasting, showing children's present nutritional state. In poor countries, the problem is more serious. The total number of malnourished children in Sub-Saharan Africa will rise to 128 million. There the share will rise from $19 \%$ to near $35 \%$ in Sub-Saharan Africa. ${ }^{9}$

In nations with high child mortality, underweight accounts for about $15 \%$ of total disability-adjusted life years (DALY) losses. ${ }^{10}$

During the pandemic, there was a significant increase in all forms of malnutrition, including wasting, with UNICEF estimating that over 6.7 million extra children were wasted. Wasting continues at alarming rates,

\footnotetext{
* Corresponding author.

E-mail addresses: wondwosenm955@gmail.com (W. Molla), argaw_dirshy@yahoo.com (D. Argaw), robelk@du.edu.et (R.H. Kabthymer), are.wud16@gmail.com (A. Wudneh).
} 
necessitating a change of course if the 2030 objective is to be met. $^{7}$

The active growth era of childhood is the school years. ${ }^{11}$ The primary school years are a period of rapid physical and mental development for children. According to research, poor nutrition is one of the most common factors of low school enrolment, excessive absenteeism, early dropout, and bad classroom performance among primary school-aged children $^{12}$

Malnutrition has a psychological, biological, and social impact on children and adolescents; however, their mental, social, and physical well-being are crucial instruments for a society's economic and social development. ${ }^{13}$ Poor growth is caused by a number of issues that are linked to overall living standards and people's capacity to meet their fundamental requirements, such as food, housing, and health care. Growth assessment is the single most important metric for determining a child's nutritional and health status. Malnutrition is one of the major factors why children perform poorly in school. ${ }^{14,15}$

Wasting is associated with multiple factors at the immediate, underlying, and basic levels. The immediate factors include low energy and nutrient intake, nutrient loss due to infection, or a combination of both low energy or protein intake and high nutrient loss by the mother during pregnancy or by the child after birth. The significant underlying factors include maternal characteristics of BMI, height, and education, as well as socio-economic status, and access to services, including water, sanitation, and hygiene services. ${ }^{16}$ Many researches support the interplay between wasting and factors associated with it. For instance, the study conducted in Kenya stated the proportion of wasting among public primary school children was $20(9.7 \%)^{17}$

Malnutrition is caused by a variety of factors, including family size, ethnicity, parental education, parental occupation, and family income. Increased income has an impact on the reduction of undernutrition. Other factors, such as education level, have a significant impact on lowering malnutrition. ${ }^{12,14,18,19}$ The underlying determinants of nutrition in Ethiopia are lack of care for vulnerable segments of the population, environmental hygiene, inadequate health services, and household food insecurity. ${ }^{14,18,20}$

School-aged children in Ethiopia are routinely excluded from health and nutrition surveys and surveillance. Despite the fact that wasting is a persistent problem in underdeveloped countries like Ethiopia, there is a distinct shortage of information on the nutritional condition of children in this age group. Despite the fact that this is a critical age range for determining children's academic performance, there is no clear data indicating the magnitude of wasting in this age range of children across Africa or at the country level. Malnutrition in young children under the age of five is the focus of the majority of the study, particularly in poor nations. In addition to this, there is a limited study on the prevalence and associated factors of wasting in schoolchildren, especially during the pandemic. And the frequent instability of the population in some parts of Ethiopia, including the study area and its association with the nutritional status of the residents was not investigated yet, particularly in this age group of children. Therefore, this study aimed to assess the prevalence of wasting and its associated factors among school-aged children in Ethiopia during the era of the covid-19 pandemic.

\section{Methods and material}

\subsection{Study area and design}

School based cross-sectional study was conducted in Gedeo Zone, South Ethiopia, from May-June 2021 GC. There are six districts, two city administrations with 31 urban and 133 rural kebeles (the smallest administration unit) with one university, one teacher's education college, primary and secondary schools, one in the zone. The 2007 Census conducted by the CSAE reports that this Zone has a total population of 847,434 , of whom 424,742 are men and 422,692 women. While 107,781 or $12.72 \%$ are urban inhabitants. A total of 179,677 households were counted in this zone, which results in an average of 4.72 persons with a household and 172,782 housing units.

\subsection{Population}

All school children's who were attending in primary school in Gedeo zone were the source population of this study. From those, all randomly selected students who were attended, primary schools in the selected schools and districts of the zone were the study population of this study. All children with the age range of 6-14 years who were attended in the selected schools were included in the study. Whereas children whose age unknown, those who were seriously ill and had physical deformities of limbs and spines were excluded from this study because of difficulty in height measurement.

\subsection{Sample size determination}

The sample size was determined by using a single population proportion formula $(n=(Z / 2) 2 p(1 p) / d 2)$ with the assumption of confidence interval, $95 \%$ margin of error $5 \%$ and prevalence of wasting (20.8\%) in the study conducted in Fogera and Libo Kemkem districts, Ethiopia. ${ }^{6}$ And by considering the design effect, the sample size was then multiplied by 2 and for a possible to none response rate during the study, the sample size was increased by $5 \%$ to: $n=531$.

\subsection{Sampling technique and sampling procedures}

A multistage sampling technique was used. Initially, out of six districts of the zone, three districts were selected by using simple random sampling techniques (lottery method). Then, nine primary schools were selected from three districts of the zone. Then, the final sample size was allocated proportionally for each primary school based on the number of their students. From each selected school, study participants were selected by using a simple random sampling method after developing the sampling frame having a list of students which were obtained from their school (students' roster).

\subsection{Data collection and anthropometric measurements}

A structured questionnaire was adapted from the nutrition baseline survey report for the National Nutrition Program of Ethiopia by Ethiopian Public Health Institute (EPHI). The questionnaire was prepared in English and then translated to Amharic and Gedieo Ouffa languages, then back-translated to English by an independent translator for its consistency. The questionnaires were administered in Amharic.

Two days training was given for data collectors and supervisors on the objectives of the study, data collection procedures, data collection instruments, and physical measurement.

Household food insecurity assessment (HFIAS), HFSS was assessed by using a nine-item standard questionnaire developed by Food and Nutrition Technical Assistance project (FANTA). ${ }^{6}$

This tool has been validated and is being used in developing countries. ${ }^{21}$ When a household takes less than two of the 27 food insecurity indicators, it is considered as food secured. The HHFS questionnaire had four response options: "never," "rarely," "sometimes," and "often." Food secure households were identified when respondents said they were "never" or "rarely" concerned that their households would not have enough food. Mild food insecure households were defined as those that sometimes or often worried about not having enough food and/or were unable to eat favorite foods and/or rarely ate a more monotonous diet than desired. Households that reported that they rarely or sometimes ate more monotonous diets than desired sometimes or often, and/or had started to cut back on quantity by reducing the size of meals or number of meals were coded as moderately food insecure. ${ }^{22}$ 


\subsection{Dietary assessment}

To determine food consumption patterns and dietary diversity (DDS), a modified version of the Helen Keller International FFQ and a 24-h dietary recall were used, respectively. ${ }^{23}$

Dietary diversity score (the number of food groups the child consumed during the 24 -h preceding the survey) was used as a proxy for dietary diversity (14). It was calculated and divided into two categories of adequate or inadequate dietary diversity (i.e., consumption of $<4$ or $\geq 4$ food groups) based on the WHO guidelines, within the seven food groups in $24 \mathrm{~h}$.

\subsection{Assessment of anthropometric variables}

Children's heights and weight were recorded according to World Health Organization. (WHO) guidelines to generate anthropometric variables. $^{24}$

Height: Height was measured without shoes and in a standing position. The height of each child was measured in Frankfurt position (head, shoulder, buttocks, knee, and heal touch vertical board) to the nearest $0.1 \mathrm{~cm}$ by using a Tanita HR-200 stadiometer.

Weight: Using the standard calibration weight of $2 \mathrm{~kg}$ iron bars, the weighting scale was calibrated and checked daily. Using a Tanita BWB 800 weighing digital electronic scale, body weight was measured to the nearest $0.1 \mathrm{~kg}$ without shoes and while wearing minimal clothing. The measurements of height and weight were taken three times and the average value was recorded. Wasting was assessed by measuring weightfor-height of equal to or less than minus two standard deviations (2 SD) below the mean of a reference WHO standard by using Anthro Plus 1.0.4 software program (13). Children were classified as wasted: if the child's weight for age Z-score is $<-2$ SD from the median WHO reference values. $^{25}$

\subsection{Data analysis}

Data were checked for completeness, edited, and coded. The data was entered by using Epi data version 3.1 software and then exported to SPSS version 23.0 statistical software for analysis. The $\mathrm{Z}$ score value for weight-for-height was calculated using the ANTHRO PLUS software. ${ }^{24}$ Descriptive statistics such as mean, median, frequency, and percentage were used. Bivariate analysis was done and all explanatory variables with P-value less than 0.25 was regressed on to multivariable analysis. Multivariable analysis was employed to determine an independent determinant factor among explanatory variables. Adjusted odds ratio (AOR), 95\% CI, and P-value less than or equal to 0.05 was used to decide a statistically significant association with the outcome variable. Model fitness was assessed by using Hosmer and Lemeshow test with p-value of ( $p>0.756$ ). Multicollinearity was checked by using variance inflation factor (VIF) and tolerance test. The result of VIF was less than 2 while the tolerance test was greater than 0.1 , which was within the normal limit. The findings of this study were presented in the form of text, charts, and tables.

\section{Results}

\subsection{Socio demographic characteristics of study participants}

A total of five hundred primary school children with their mother or caregivers were participated making a response rate of $94.2 \%$ (absence of participants after repeated visits was one of the factors for nonresponse). From the total of five hundred of the participants, the majority $319(63.8 \%)$ of them were found in age between 10 and 14 years, while the rest $181(36.2 \%)$ of them were found in age between 6 and 9 years with the mean and + SD age of children being 10 and \pm 2 respectively. Almost half 258 (51.6\%) of the children who took part in the study were male, $407(81.4 \%)$ of them were protestant in religion followed by $60(6.0 \%)$ were orthodox. The majority $159(31.8 \%)$ of mothers or care givers were unable to read and write, $221(44.2 \%)$ of them were housewives, 400 (80.0\%) of the children were living in food in-secured households. Furthermore, $406(81.2 \%)$ of the children were originating from monogamy families while the rest $94(18.8 \%)$ of the children were originating from polygamy, see Table 1.

\subsection{Child health status, dieting habits, and sanitation practices}

Consumption of staple foods by children, more than half, 317 (63.4\%) of them were reported that "Encet" as predominant locally made foods followed by 175 (35.0) were reported "Enjera". Around 458 (91.6\%) of the participants had less than three meal frequencies per day, in addition to that more than two hundred twenty-six (45.2\%) students had a habit of missing any of the meal schedule. Only 185 (37.0\%) of the children were met the requirement of minimum dietary diversity per 24 h. Majority (89.6\%) of them had improved water sources. Almost one in two children (57.6\%) had illness or infection in the last two weeks prior to the survey, $268(53.6 \%)$ of the children had a functional latrine at their home, 255 (51.0\%) of them had the habit of washing their hands before eating, while $449(89.8 \%) \%$ ) of them had the habit of washing

Table 1

Socio-demographic characteristics of school children and their families in the selected primary schools in Gedeo zone, South, Ethiopia, 2021.

\begin{tabular}{|c|c|c|c|}
\hline Variables & Category & Frequency & Percentage \\
\hline \multirow[t]{2}{*}{ Age of child (in year) } & $6-9$ & 181 & 36.2 \\
\hline & $10-14$ & 319 & 63.8 \\
\hline \multirow[t]{2}{*}{ Child sex } & Male & 258 & 51.6 \\
\hline & Female & 242 & 48.4 \\
\hline \multirow[t]{2}{*}{ Grade } & $1-4$ & 293 & 58.6 \\
\hline & $5-8$ & 207 & 41.4 \\
\hline \multirow[t]{4}{*}{ Religion of parent/care giver } & Protestant & 407 & 81.4 \\
\hline & Orthodox & 60 & 6.0 \\
\hline & Muslim & 30 & 12.0 \\
\hline & Others & 3 & 0.6 \\
\hline \multirow{4}{*}{$\begin{array}{l}\text { Educational status of } \\
\text { mothers/care takers }\end{array}$} & Illiterate & 159 & 31.8 \\
\hline & Primary level & 131 & 26.2 \\
\hline & Secondary level & 136 & 27.2 \\
\hline & College and above & 74 & 14.8 \\
\hline \multirow{4}{*}{ Educational status of father } & Illiterate & 60 & 12.0 \\
\hline & Primary level & 109 & 21.8 \\
\hline & Secondary level & 112 & 22.4 \\
\hline & College and above & 156 & 31.2 \\
\hline \multirow{5}{*}{$\begin{array}{l}\text { Occupation of mother/care } \\
\text { giver }\end{array}$} & Housewife & 221 & 44.2 \\
\hline & $\begin{array}{l}\text { Governmental } \\
\text { employee }\end{array}$ & 94 & 18.8 \\
\hline & $\begin{array}{l}\text { Nongovernmental } \\
\text { employee }\end{array}$ & 15 & 3.0 \\
\hline & Daily laborer & 20 & 4.0 \\
\hline & Private/merchant & 129 & 25.8 \\
\hline \multirow[t]{6}{*}{ Occupation of father } & Farmer & 96 & 19.2 \\
\hline & $\begin{array}{l}\text { Governmental } \\
\text { employee }\end{array}$ & 151 & 30.2 \\
\hline & $\begin{array}{l}\text { Nongovernmental } \\
\text { employee }\end{array}$ & 52 & 10.4 \\
\hline & Merchant & 91 & 18.2 \\
\hline & Daily laborer & 31 & 6.2 \\
\hline & Others & 19 & 3.8 \\
\hline \multirow[t]{2}{*}{ Family size } & $\leq 4$ & 57 & 11.4 \\
\hline & $\geq 5$ & 443 & 88.6 \\
\hline \multirow[t]{3}{*}{ Income } & $<1000$ & 141 & 28.2 \\
\hline & $1000-2000$ & 209 & 41.8 \\
\hline & $\geq 2000$ & 150 & 30.0 \\
\hline \multirow{2}{*}{$\begin{array}{l}\text { Household food security } \\
\text { status }\end{array}$} & Food secured & 100 & 20.0 \\
\hline & Food in-secured & 400 & 80.0 \\
\hline \multirow[t]{2}{*}{ Residence area } & Urban & 290 & 58.0 \\
\hline & Rural & 210 & 42.0 \\
\hline \multirow[t]{2}{*}{ Type of family } & Monogamy & 406 & 81.2 \\
\hline & Polygamy & 94 & 18.8 \\
\hline \multirow{2}{*}{$\begin{array}{l}\text { history of internal } \\
\text { displacement within the } \\
\text { last } 2 \text { years }\end{array}$} & Yes & 143 & 28.6 \\
\hline & No & 46 & 71.4 \\
\hline
\end{tabular}


their hand after meal, see Table 2.

\subsection{Prevalence of wasting among primary school-age children}

From the total of 500 primary students, 91 (18.2\%) (95\% CI: 11.4-23.8) were wasted while the rest $498(81.8 \%)$ were not wasted, as seen in Fig. 1.

\subsection{Factors associated with wasting among school-age children}

In the bivariate logistic regression analysis, child age (years), grade, sex, distance from school, mother education status, marital status, residence, stable food, frequency of meals per day, dietary diversity, history of internal displacement, family type, illness in the last two weeks, and family size were the candidate variables for multivariable analysis. Whereas in multivariable logistic regression, child age AOR = $3.15,95 \%$ CI $(2.05,8.44))$ ], sex [AOR $=3.87,95 \%$ CI $(2.73,9.03)]$. Mothers educational status [AOR 3.49 (95\% CI $(2.23,6.06))$ ] and having history of internal displacement [AOR 3.01, (95\%CI $(2.17,5.31)$ ] were significantly associated with wasting among school-age children, as see Table 3.

According to this study, the educational status of mothers had a statically significant association with being wasted on children. Children born from mothers who can't read and write were 3.4 times more likely to be wasted than those born from their mothers who had formal education [AOR 3.49 (95\%CI $(2.23,6.06))$ ]

The odds of being wasted among children who had a history of internal displacement within the last 2 years were 3.0 times more likely to be wasted than those who had't history of internal displacement within the last 2 years [AOR 3.01, (95\%CI $(2.17,5.31)$ ].

Moreover, Children who had between 10 and 14 years age group were 3.1 times more likely to be wasted than those who had an age between 6 and 9 years [AOR $=3.15$, 95\%CI $(2.05,8.44))$ ].

The odds of being wasted among female children were 3.8 times more likely to be wasted than male children $[\mathrm{AOR}=3.87,95 \% \mathrm{CI}(2.73$, 9.03)].

Table 2

Child health status, dieting habits, and sanitation practices of study participants in Gedeo zone, South, Ethiopia, 2021.

\begin{tabular}{llll}
\hline Variable & Category & Frequency & Percentage \\
\hline Frequency of meal & $>3$ & 42 & 8.4 \\
Habits of washing before going to meal & $\leq 3$ & 458 & 91.6 \\
& yes & 226 & 45.2 \\
Staple food & no & 274 & 54.8 \\
& Enjera & 175 & 35.0 \\
& Encet & 317 & 63.4 \\
Child DDS & Others & 8 & 1.6 \\
& Inadequate & 315 & 63.0 \\
Ever skipped one or more meals/day & Adequate & 185 & 37.0 \\
& yes & 226 & 45.2 \\
Illness/infection in the last two weeks & no & 274 & 54.8 \\
prior to the survey & yes & 288 & 57.6 \\
Availability of functional latrine at & no & 212 & 42.4 \\
home & yes & 232 & 46.4 \\
Presence of hand washing facility in & no & 268 & 53.6 \\
school & yes & 12 & 2.4 \\
Distance from students' home to school & no & 488 & 97.6 \\
& $<30$ mints & 287 & 57.4 \\
Water source & $\geq 30$ mints & 213 & 42.6 \\
Hand washing habit before meal & improved & 448 & 89.6 \\
Hand washing habit after meal & Unimproved & 52 & 10.4 \\
& yes & 255 & 51.0 \\
& no & 245 & 49.0 \\
& yes & 449 & 89.8 \\
& no & 51 & 10.2 \\
\hline
\end{tabular}

\section{Discussion}

\subsection{Prevalence of wasting}

According to this study, 18.2 (\%) of school-aged children suffer from wasting. This is the result of recent rapid weight loss or a lack of weight gain. Furthermore, it implies that this cohort of children's recent nutritional status in the research area was poor. This finding is comparable with the finding in Ethiopia and Nepal where about $14 \%$ and $12 \%$ of children participated had wasting, respectively, and it is also in line with the finding in Ghana where $19.4 \%$ of school-aged children had wasting respectively. ${ }^{1,26,27}$ This, finding also comparable with the finding in urban India where $20 \%$ of school children had wasting. ${ }^{28}$

Higher than the study conducted in northern Ethiopia, southern Ethiopia, and Kenya where only 9\%, 8\%, and 9.7\% percent of children had wasting respectively. ${ }^{17,29,30}$ The present finding is also higher than the study done in Pakistan where only $13 \%$ of study children had wasting. ${ }^{31}$ The disparity could be explained by the individuals' socioeconomic and cultural backgrounds. It could be linked to the conflict in the research area, which causes family instability which in turn leads to household food insecurity and malnutrition and death are common in conflict circumstances, especially among vulnerable communities (i.e., children, women, and the elderly). ${ }^{32,33}$

The finding is also much higher than the study conducted in Egypt, Mexico, and China, in which $0.9 \%, 1.1 \%$, and $9 \%$ of school children had wasting respectively. ${ }^{34}$ The difference could be due to the age category of children in the study conducted in previous researches and it may be attributed because the discrepancy in the residency of participants and sociocultural differences of the countries may explain the variation.

The present study is lower than the study conducted in central India among rural areas where $33.3 \%$ of school children had wasting. ${ }^{12}$ The difference may be attributed to the socioeconomic, cultural, and study setting variations between the two countries and the time of study may explain the difference between the two findings.

\subsection{Factors associated with wasting}

Age, maternal education, child sex, and family history of displacement were all found to be independently linked to wasting in this study.

Age of the children in this study was found to be associated with wasting. It may be explained by the fact that as the age of a child increases, the need of the body for nutrients also increases, to meet the increased need, the child should feed a high amount of food and a variety of food. However, due to the constant or steady growth of the family economy, it may not occur. The finding is in line with the study conducted in Ethiopia. ${ }^{35}$ The present study is also similar to the finding in Pakistan and India ${ }^{12,36}$

In the present study, maternal educational level were significantly associated with wasting. It indicates that children having illiterate mothers are more likely to suffer from wasting. It may be due to the lack of understanding about the health value of adequate nutrition for children among illiterate mothers. Furthermore, mothers having low educational status are less likely to manage the available food in the household. Similar findings with study in Ethiopia and Pakistan. ${ }^{35,36}$ This study also supported by the study conducted in the western region of Nepal. ${ }^{27}$ In the current study, females were more likely than males to have had wasting. This could be because females' growth and development were more influenced by environmental and gender violence (including unequal food distribution) than males', and this also probably may be due to males preferring over female to feed among Ethiopian parents is common. making females more vulnerable to wasting and other nutrition-related problems. The finding is supported by a study conducted in Kenya where girls had a high rate of wasting than boys. ${ }^{17}$

Having a history of family displacement was significantly associated with wasting in the recent study. A similar study in Nigeria on "child 


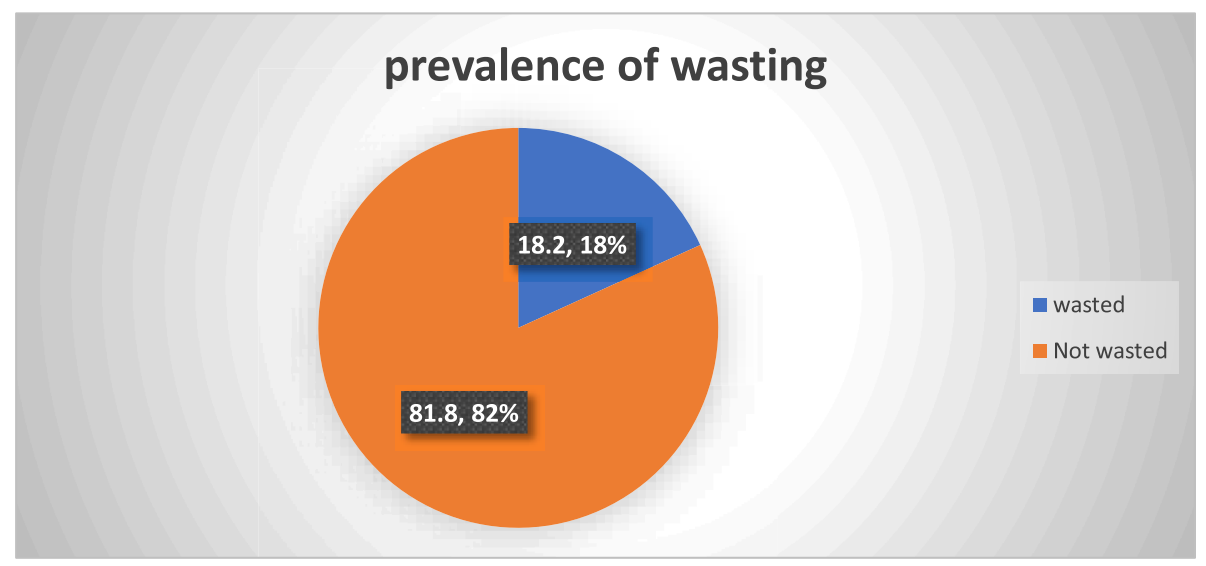

Fig. 1. Prevalence of wasting among primary school-age children in Gedeo zone, South, Ethiopia, 2021.

Table 3

Factors associated with wasting among school-age children $(n=500)$, Gedeo zone, Southern Ethiopia, 2021.

\begin{tabular}{|c|c|c|c|c|c|c|}
\hline \multirow[t]{2}{*}{ Risk factors } & \multirow[t]{2}{*}{ categories } & \multicolumn{2}{|c|}{ wasting } & \multirow[t]{2}{*}{ COR $(95 \% \mathrm{CI})$} & \multirow[t]{2}{*}{ AOR $(95 \% \mathrm{CI})$} & \multirow[t]{2}{*}{$P$ value } \\
\hline & & Yes & No & & & \\
\hline \multirow[t]{2}{*}{ Age (years) } & $6-9$ & 20 & 161 & 1 & 1 & \\
\hline & $10-14$ & 71 & 248 & $3.55(1.39,9.59)$ * & $3.15(2.05,8.44)$ & 0.01 \\
\hline \multirow[t]{2}{*}{ Child sex } & Male & 23 & 235 & 1 & 1 & \\
\hline & Female & 68 & 174 & $3.99(1.93,6.65)$ * & $3.87(2.73,9.03)$ & 0.01 \\
\hline \multirow[t]{2}{*}{ Grade } & $1-4$ & 41 & 252 & 1 & & \\
\hline & $5-8$ & 50 & 157 & $1.94(1.28,2.84) * *$ & & \\
\hline \multirow[t]{4}{*}{ Mother education } & Illiterate & 50 & 109 & $3.784(2.85,6.90) *$ & $3.49(2.23,6.06)$ & 0.01 \\
\hline & Elementary & 27 & 104 & $2.14(1.67,3.85) *$ & $2.01(1.14,3.49)$ & 0.03 \\
\hline & Secondary & 24 & 112 & $1.762(1.76,3.85) * *$ & $1.39(1.07,2.86)$ & 0.05 \\
\hline & College & 8 & 66 & 1 & 1 & \\
\hline \multirow[t]{2}{*}{ Type of family } & Monogamy & 71 & 335 & 1 & & \\
\hline & Polygamy & 20 & 74 & $1.27(1.05,1.71) * *$ & & \\
\hline \multirow[t]{3}{*}{ Staple food } & Enjera & 22 & 153 & 1 & & \\
\hline & Encet & 67 & 250 & $1.86(1.33,2.93) * *$ & & \\
\hline & Other & 2 & 6 & $2.03(1.51,2.60) * *$ & & \\
\hline \multirow[t]{2}{*}{ Dietary diversity } & Adequate & 22 & 153 & 1 & & \\
\hline & Inadequate & 69 & 246 & $1.93(1.49,4.01)$ * & & \\
\hline \multirow[t]{2}{*}{ Meal frequency } & $<3$ & 11 & 31 & $0.59(0.86,1.51) * *$ & & \\
\hline & $>3$ & 80 & 378 & 1 & & \\
\hline \multirow[t]{2}{*}{ Illness in the last two weeks } & Yes & 58 & 240 & $0.9(0.9,1.63) * *$ & & \\
\hline & No & 44 & 168 & 1 & & \\
\hline \multirow[t]{2}{*}{ Family size } & $\leq 4$ & 10 & 47 & 1 & & \\
\hline & $\geq 5$ & 81 & 362 & $1.05(1.21,2.17) * *$ & & \\
\hline \multirow[t]{2}{*}{ Residence } & Urban & 24 & 267 & $2.06(1.17,2.86) * *$ & & \\
\hline & Rural & 11 & 198 & & & \\
\hline \multirow[t]{2}{*}{ Having internal displacement within the last 2 years } & Yes & 45 & 98 & $3.10(2.29,5.25)$ * & $3.01(2.17,5.31)$ & 0.01 \\
\hline & No & 46 & 311 & 1 & 1 & \\
\hline \multirow[t]{2}{*}{ Distance from school } & $<30 \mathrm{~min}$ & 22 & 265 & $1.633(1.16,3.84) * *$ & & \\
\hline & $\geq 30 \mathrm{~min}$ & 13 & 200 & 1 & & \\
\hline
\end{tabular}

Not: $*=\mathrm{p}<0.05, * *=\mathrm{p}<0.01$, AOR $=$ Adjusted Odd Ratio; CI = Confidence Interval, COR = Crude Odd Ratio.

nutrition during conflict and displacement" backs up the present finding where displacement was associated with a $57 \%$ increase in the likelihood of acute malnutrition (wasting). ${ }^{32}$ Surveys coordinated by UNICEF in vulnerable areas of horn Africa including Ethiopia revealed a supportive findings where internally displaced children had higher prevalence rates of wasting. ${ }^{37}$ It may be due to the instability of the family and loss of property that leads to food insecurity within the households. As it takes a long time for the family to become stable and regain property. And it is not surprising for the child to have had wasting since it is a double burden in developing countries to have a history of displacement.

\section{Conclusions and recommendations}

More than $18 \%$ of primary school children had wasted in this study. The age of children, maternal education, history of internal displacement, and sex of children were significantly associated factors with wasting. As a result of this finding, it is necessary to implement school health and nutrition initiatives to improve the nutritional status of school-age children in the study area. The interventions should be targeted with a special emphasis on the vulnerable group of children (history of internal displacement). Considering nutritional education, more about child development patterns and improving parenting skills should also be targeted.

\section{Ethics approval and consent to participate}

Ethical approval and clearance were obtained from Institutional Review Board (IRB) of Dilla University, college of Medicine and Health science. Official letters were submitted to all respective school managers. Permission was also obtained from the concerned bodies. Since the study participants were aged less than 18 , both oral and written 
consent were obtained from all participants and their parents/legal guardians (legally authorized representatives) after a brief explanation about the purpose and objectives of the study. Participants' involvement in the study was totally voluntary basis, and those who were unwilling to participate in the study \& those who wished to quit their participation at any stage were informed to do so without any restriction. Confidentiality was maintained at all levels of the study by namelessly by avoiding the name of the participants in the questionnaire. The collected data were kept under lock and key for security and used only for the purpose of the study.

\section{Consent for publication}

Not applicable.

\section{Availability of data and materials}

All data included in this manuscript can be accessed from the corresponding author upon request through the email address.

\section{Funding}

This study was not funded by any grant. There have been no reimbursements, fees, funding, nor salary from any organization that depends on or influence the results and publication of this study.

\section{Author contributions}

(WM) conceptualized, designed the study, collect, analyzed and interpretation of the data and drafting of the manuscript. (RH), (DW), and (AW) Designed the study, analyzed and interpretation of the data and drafting of the manuscript, and advised the whole research paper.

\section{Declaration of competing interest}

The authors declare that they have no competing interests.

\section{Acknowledgements}

We are thankful to the study participants for giving their fruitful time to participate in this study and for their unlimited support throughout the data collection.

\section{Abbreviations}

$\begin{array}{ll}\text { AOR } & \text { Adjusted Odds Ratio } \\ \text { CI } & \text { Confidence Interval } \\ \text { COR } & \text { Crude Odds Ratio } \\ \text { DD } & \text { Dietary diversity } \\ \text { EPHI } & \text { Ethiopian Public Health Institute } \\ \text { EPIDATA } & \text { Epidemiological Data Version } \\ \text { EPIINFO } & \text { Epidemiological Information } \\ \text { FANTA } & \text { Food and Nutrition Technical Assistance project } \\ \text { HFIAS } & \text { Household Food Insecurity Access Scale } \\ \text { HHFS } & \text { Household Food Security } \\ \text { KM } & \text { Kilo Meters } \\ \text { OR } & \text { Odds Ratio } \\ \text { SD } & \text { Standard Deviation } \\ \text { SNNPR } & \text { South Nations Nationalities and Peoples Region } \\ \text { SPSS } & \text { Statistical Package for the Social Sciences } \\ \text { USA } & \text { United States, of America } \\ \text { VIF } & \text { variance inflation factor } \\ \text { WHO } & \text { World Health Organization }\end{array}$

\section{References}

1 Wolde M, Berhan Y, Chala A. Determinants of underweight, stunting, and wasting among schoolchildren. BMC Publ Health. 2015;15(1):1-9.

2 Mulugeta M, Tiruneh G, Alemu ZA. Magnitude and associated factors of household food insecurity in Fedis Woreda, East Hararghe zone, Oromia region, Ethiopia. Agric Food Secur. 2018;7(1):1-8.

3 Assemie MA, Alamneh AA, Ketema DB, et al. High burden of undernutrition among primary school-aged children and its determinant factors in Ethiopia; a systematic review and meta-analysis. Ital. J Pediatr. 2020;46(1):1-14. Hunt JM. The potential impact of reducing global malnutrition on poverty reduction and economic development. Asia Pacific Journal of Clinical Nutrition. 2005;14.

4 Younis K, Ahmad S, Badpa A. Malnutrition: causes and strategies. J Food Process Technol. 2015;6(434):2.

5 WHO Multicentre Growth Reference Study Group. WHO Child Growth Standards based on length/height, weight and age. Acta Paediatr Suppl. 2006;450:76-85.

6 Herrador Z, Sordo L, Gadisa E, et al. Cross-sectional study of malnutrition and associated factors among school aged children in rural and urban settings of Fogera and Libo Kemkem districts, Ethiopia. PLoS One. 2014;9(9), e105880.

7 Obembe TA, Wu Adenuga, Asuzu MC. Determinants of wasting among schoolchildren in a Southwestern state of Nigeria: implications to strengthen the nutritional component of primary health-care model. J Fam Med Prim Care. 2018;7 (4):671.

8 Frongillo Jr EA, de Onis M, Hanson KMP. Socioeconomic and demographic factors are associated with worldwide patterns of stunting and wasting of children. $J$ Nutr. 1997;127(12):2302-2309.

9 Sheehy T, Carey E, Sharma S, Biadgilign S. Trends in energy and nutrient supply in Ethiopia: a perspective from FAO food balance sheets. Nutr J. 2019;18:46. PMID: 31409356.

10 Rodgers A, Ezzati M, Vander Hoorn S, et al. Distribution of major health risks: findings from the Global Burden of Disease study. PLoS Med. 2004;1(1):e27. Danaei G, Andrews KG, Sudfeld CR, Fink G, McCoy DC, Peet E, et al. Risk factors for childhood stunting in 137 developing countries: a comparative risk assessment analysis at global, regional, and country levels. PLoS medicine. 2016;13(11): e1002164.

11 1471-2393-13-229.pdf $>$.

12 Srivastava A, Mahmood SE, Srivastava PM, Shrotriya VP, Kumar B. Nutritional status of school-age children-A scenario of urban slums in India. Arch Publ Health. 2012;70 (1):1-8.

13 Pal I. Fighting malnutrition and reaching sustainable development goals through school farming (during the COVID-19 pandemic). School Farms: Feeding and Educating Children; 2021:48.

14 Admasie A, Ali A, Kumie A. Assessment of demographic, health and nutrition related factors to a school performance among school children in Arb-Gebeya Town, TachGaynt Woreda, South Gondar, Ethiopia. Ethiop J Health Dev. 2013;27(2):104-110.

15 UNICEF. The cost of hunger in Ethiopia. In: The Social and Economic Impact of Child Undernourishment in Ethiopia Summary Report Addis Ababa. UNICEF; 2014.

16 World Health O. UNICEF/WHO/The World Bank Group Joint Child Malnutrition Estimates: levels and trends in child malnutrition: key findings of the 2020 edition. In: 2020,Nutrition IC. The Achievable Imperative for Global Progress New York. New York, NY, USA: NY United Nations Children's Fund; 2013.

17 Mwaniki E, Makokha A. Nutrition status and associated factors among children in public primary schools in Dagoretti, Nairobi, Kenya. Afr Health Sci. 2013;13(1): 38-46.

18 Benson T, Bellete S, Chanyalew D, Belachew T. An Assessment of the Causes of Malnutrition in Ethiopia. International Food Policy Research Institute Washington DC; 2005:1-213.

19 Best C, Neufingerl N, Van Geel L, van den Briel T, Osendarp S. The nutritional status of school-aged children: why should we care? Food Nutr Bull. 2010;31(3):400-417.

20 Abebe F, Geleto A, Sena L, Hailu C. Predictors of academic performance with due focus on undernutrition among students attending primary schools of Hawa Gelan district, Southwest Ethiopia: a school based cross sectional study. BMC nutrition. 2017;3(1):1-8.

21 Degarege D, Degarege A, Animut A. Undernutrition and associated risk factors among school age children in Addis Ababa, Ethiopia. BMC Publ Health. 2015;15(1): $1-9$.

22 Mitchell R. Implementing children's rights in British Columbia using the population health framework. Int'l J Child Rts. 2000;8:333.

23 Wuehler SE, Coulibaly M. Situational analysis of infant and young child nutrition policies and programmatic activities in Mali. Matern Child Nutr. 2011;7:83-112.

24 Wolde T, Belachew T. Chronic undernutrition (stunting) is detrimental to academic performance among primary schools of adolescent children: a randomized cross sectional survey in Southern Ethiopia. BMC Res Notes. 2019;12(1):1-6.

25 Status WP. The use and interpretation of anthropometry. WHO Tech Rep Ser. 1995; 854(9).

26 Danquah AO, Amoah AN, Opare-Obisaw C. Nutritional status of upper primary school pupils in a rural setting in Ghana. Int J Nutr Food Sci. 2013;2(6):320.

27 Hs J, Gupta R, Joshi M, Vipul M. Determinants of nutritional status of school children-a cross sectional study in the western region of Nepal. Njirm. 2011;2(1): $1-13$.

28 Patil CR, Thakre SS, Khamgaonkar MB, Thakre S. Prevalence of stunting and wasting among Anganwadi school children of rural and urban area of Central India: a crosssectional study. Int J Med Sci Publ Health. 2017;6(2):413.

29 Getaneh Z, Melku M, Geta M, Melak T, Hunegnaw MT. Prevalence and determinants of stunting and wasting among public primary school children in Gondar town, northwest, Ethiopia. BMC Pediatr. 2019;19(1):207. 
30 Tariku EZ, Abebe GA, Melketsedik ZA, Gutema BT. Prevalence and factors associated with stunting and thinness among school-age children in arba minch health and demographic surveillance site, southern Ethiopia. PLoS One. 2018;13(11), e0206659.

31 Mian RM, Ali M, Ferroni PA, Underwood P. The nutritional status of school-aged children in an urban squatter settlement in Pakistan. Pakistan J Nutr. 2002;1(3): 121-123.

32 Iacoella F, Tirivayi N. Child nutrition during conflict and displacement: evidence from areas affected by the Boko Haram insurgency in Nigeria. Publ Health. 2020;183: 132-137.

33 Machel G. Impact of Armed Conflict on Children: UN New York. 1996. Wessells MG. The changing nature of armed conflict and its implications for children: The Graça Machel/UN study. Peace and Conflict. 1998;4(4):321-334,Kinyoki DK, Moloney GM, Uthman OA, Kandala N-B, Odundo EO, Noor AM, et al. Conflict in Somalia: impact on child undernutrition. BMJ global health. 2017;2(2):e000262.

34 Abdel Wahed WY, Hassan SK, Eldessouki R. Malnutrition and its associated factors among rural school children in fayoum governorate, Egypt. Journal of Environmental and Public Health. 2017:4783791. Fang Y, Zhao L, Yu D, Fang H, Yu W, Guo Q, et al. Prevalence of stunting and wasting among children and adolescents aged 6 to 17 years in 2010-2012 in China. Wei sheng yan jiu= Journal of hygiene research. 2018; 47(1):27-31,Monarrez-Espino J, Martinez H, Martínez V, Greiner T. Nutritional status of indigenous children at boarding schools in northern Mexico. European journal of clinical nutrition. 2004;58(3):532-40.

35 Getaneh Z, Melku M, Geta M, Melak T, Hunegnaw MT. Prevalence and determinants of stunting and wasting among public primary school children in Gondar town, northwest, Ethiopia. BMC Pediatr. 2019;19(1):1-11.

36 Mushtaq MU, Gull S, Khurshid U, Shahid U, Shad MA, Siddiqui AM. Prevalence and socio-demographic correlates of stunting and thinness among Pakistani primary school children. BMC Publ Health. 2011;11(1):1-12.

37 Chotard S, Mason JB, Oliphant NP, Mebrahtu S, Hailey P. Fluctuations in wasting in vulnerable child populations in the Greater Horn of Africa. Food Nutr Bull. 2010;31 (3_suppl3):S219-S233. 